\title{
Outdoor journeys as a catalyst for enhanced place connectedness and environmental stewardship
}

\author{
Nicholas R. Schwass ${ }^{1}$ - Stephanie E. Potter ${ }^{1} \cdot$ Timothy S. O'Connell $^{2}$ • \\ Tom G. Potter ${ }^{1}$ (D)
}

Accepted: 4 February 2021/ Published online: 23 March 2021

(C) Outdoor Education Australia 2021

\begin{abstract}
Humans struggle to comprehend, appreciate, and protect natural environments when they have had minimal or no exposure to these spaces. While there are many theoretical explanations for this bifurcation between humans and nature, there is an absence of wide-ranging solutions to address the issue. With a dramatic global shift towards a swelling urban culture driven by technology, current research strongly emphasizes the importance of nature's health benefits. This study investigates the weakening connections between humans and the natural world and the effect that the characteristics and processes of nature-based journeys have on individual perspectives of environmental awareness and stewardship. Using qualitative research methods, nine participants from three Outward Bound Canada expeditions were interviewed to explore how outdoor journeys of at least one week in length influenced their sense of environmental connectivity and/or stewardship. Results demonstrate a positive association between participants' exposure to natural environments and an increased sense of connection and stewardship towards nature. Participants experienced a reduced sense of fear in outdoor environments while their comfort levels in natural areas grew. Their values associated with natural areas changed, and for a few, their journeys challenged them to question their current personal and employment situation. Their journeys also augmented naturalistic understanding, increased their sense of connection with their surroundings, nurtured a desire to continue visiting natural areas and, for most, inspired their will to participate in employment or volunteer initiatives to improve the state of the environment.
\end{abstract}

Keywords Nature · Natural environments · Stewardship · Environmental connectivity · Environmental awareness

Nicholas R. Schwass

nicholas_schwass@outlook.com

Extended author information available on the last page of the article 
Time spent in place, indoors or out, urban or rural, often cultivates a sense of attachment (Hidalgo and Hernandez 2001), especially when developed through cultural learning (Beery et al. 2015). As global culture becomes more urban, a simultaneous detachment from natural places has led to erroneous understatements of nature's significance and of our dependence on it (Grimm et al. 2008; Schultz et al. 2005; Wyles et al. 2019). As humans become further detached from the natural world, we tend to neglect the essential impacts of nature on human psychology and physical and mental health (Barton and Pretty 2010; Daily 2012). But despite this detachment, research shows that natural places can rejuvenate these holistic needs (Berto 2014; Lumber et al. 2017; Wyles et al. 2019).

The presence and enjoyment of natural places is important to human life (Daily 2012; Daily et al. 2000). Recently, this has been thrust into the spotlight as the COVID19 pandemic forced area closures and stay-at-home directives that prevented people from accessing natural areas for recreation and leisure pursuits (O'Connell et al. 2020; Rice et al. 2020; Samuelsson et al. 2020). As natural areas gradually reopened, it was overwhelmingly clear how important natural places are to people (both regular users and new users) as evident through overflowing parking lots, crowded trails, and increased environmental impacts (O'Connell et al. 2020; Rice et al. 2020; Samba and Seucharan 2020). With urbanization causing limited exposure to natural places (Grimm et al. 2008; United Nations 2014), and despite renewed interest in natural places due to the impact of the COVID-19 pandemic, it begs the question if people can fully understand, appreciate, and be motivated to protect these important spaces (Beery et al. 2015; Canadian Parks Council 2014; Nisbet et al. 2009).

Concern for this is clear among researchers, environmentalists, park authorities, and other agencies supporting the protection and management of natural spaces (Canadian Parks Council 2014; Manning 2011; Selhub and Logan 2014; White et al. 2008), as time spent in nature is shown to support the development of stewardship and environmentally conscious or sustainable practices (Baird et al. 2020; Beery et al. 2015; Chapin and Knapp 2015). Research has sought to explain this divergence of humans and nature (Beery et al. 2015; Louv 2008, 2011), and to address the absence of wideranging solutions to address the growing disconnect (Barker 2007; Beery and WolfWatz 2014) and its subsequent impact on sustainable practices (Beery et al. 2015). In developed nations, education is used primarily to address sustainable use of outdoor environments, where degradation-causing activities are dissected to illustrate where change can support long-term goals that foster environmental sustainability (Christensen et al. 2002). However, strategies infrequently involve engaging people in natural environments to foster relationships with specific natural places.

One exception to this general rule of infrequent immersion of people in natural places is outdoor adventure education programming offered, for example by the National Outdoor Leadership School (NOLS) and Outward Bound Canada (OBC). These programs are typically structured to foster group development, technical skills training, leadership (including judgement and decision-making), personal growth, and enhanced connections to the natural places in which the activities occur (Ewert and Davison 2017; National Outdoor Leadership School 2020; Outward Bound Canada 2021). Outdoor adventure education activities typically involve self-propelled travel, such as backpacking or canoeing, occur in wilderness or natural places, have an element of perceived risk, and depend on a journey in the natural environment to foster participant growth (Martin et al. 2017). 
Enhanced stewardship behaviours resulting from participation in outdoor adventure education programs are well-documented and the factors that foster this change have been well studied through a qualitative lens (Beery and Wolf-Watz 2014). However, little is known about how the characteristics and processes of experiences in specific natural places extend to one's connection with nature more broadly (Beery et al. 2015; Beery and Wolf-Watz 2014). Therefore, the purpose of this research was to explore how the characteristics and processes of experiences on place-based wilderness journeys develop participants' relationships with natural places and perceptions of environmental stewardship. The research also examined how the characteristics and processes of these experiences contribute to people's connections to natural places and forecast environmental stewardship. Physical aspects of place that cause individuals to bond with place (i.e., place bonding), or become attached to a place (i.e., place attachment), can help foster stewardship behaviours and have both physical and socio-cultural dimensions (Beery and Wolf-Watz 2014). It is the interplay of the physical and social nature of places that occurs in wilderness journeys that assists in promoting environmental connectedness. As Beery and Wolf-Watz (2014) note, “... there are still reasons to believe that recreational settings, places, may facilitate and frame interpersonal relationships, social formation and behaviour" (p. 204). In other words, a journey, centred in a natural place that is interpreted through the shared experience of individuals (i.e., cultural learning), can promote place connectedness and foster environmental stewardship. However, questions remain about how this phenomenon unfolds.

\section{Nature on our minds - a review of the literature}

The term "environmental connectedness" is used throughout this paper. However, this term is subjective. "Connectedness with nature is seen as a personal disposition relevant for environmental as well as human health" (Cervinka et al. 2011, p. 50). Because "connectedness" has multiple interpretations, its delineation is fluid. As recommended by Beery and Wolf-Watz (2014), place is used in this article (instead of nature) when referencing connectedness to resist the material/objective viewpoint that historical environmental connectedness perspectives espouse. This highlights the relational aspect of specific natural spaces that is often minimized in the contemporary thinking underpinning the conceptualization of environmental connectedness (Beery and WolfWatz 2014). We (all four authors of this paper) also recognize that our experiences in and perspectives of natural places and wilderness journeys are shaped by our social location. We identify as white, upper-middle class, educated, able-bodied outdoor enthusiasts and acknowledge the complexity of factors that may frame unique experiences for others.

Canada is becoming a highly urbanized country, with more than half of its population living within the greater Toronto, Vancouver, Montreal, and Calgary/Edmonton areas (Jager and Halpenny 2012), and over 90\% of new Canadians settling in these major urban regions (Aizlewood et al. 2006; Statistics Canada 2017). Despite the evidence supporting the necessity of time in nature and natural places, a dramatic rise in urbanization and electronic entertainment media has led to an unprecedented disassociation between humans and natural places (Kareiva 2008; Louv 2008; Manning 
2011; Pergams and Zaradic 2008). Among other impacts, research indicates, for example, that youth exposed to more than two hours of screen time per day are more likely to experience impacts to their mental and physical health, such as anxiety (Berto 2014), obesity, and diabetes (Boone et al. 2007; Martin 2011).

Conversely, Martin's (2011) study revealed that time spent in natural places is more likely to foreshadow physical activity, encourage the development of motor skills, facilitate learning and cognitive development, and reduce stress while ameliorating mental health. Numerous phrases and terms have been coined to encapsulate the sedentary lifestyle described above, including "videophilia," "extinction of experience" (Pergams and Zaradic 2008), and "Nature Deficit Disorder" (Louv 2008). As non-medical terms that encapsulate the cognitive, behavioural, and social issues generated by a deficiency in human nature-based exposure, they increasingly describe the physical and emotional separation of humans from natural places now accepted as part of Western culture.

Discussions about exposure to nature also intertwine the dependence of natural places' health on current human connections to them. Many (e.g., Brooks, as cited in Louv 2011; Chapin and Knapp 2015; Klein 2017; Selhub and Logan 2014) suggest that immersion in natural places is essential to fostering environmental awareness, empathy for nature, and stewardship. As defined by the Canadian Parks Council (2014), stewardship means "conserving, restoring, and enhancing ecological and cultural resources, and maintaining biological diversity in representative, significant, and formally protected areas of land and water" (p. 34). This definition implies a willingness to act upon real change, which requires the extension of one's attachment to a natural area and places in nature. For example, Chipeniuk (1995) found that childhood foraging foreshadows knowledge and concern for biodiversity later in life, and others (e.g., Halpenny 2010; Nisbet et al. 2009; Vaske and Kobrin 2001) found that place attachment is a prediction of pro-environment behaviours. Hill and Brown (2014) argue that sustainable, pro-environmental behaviours can be encouraged through place-responsive education, or teaching and learning "by-means-of-an-environment" (Mannion et al. 2013) with a goal of improving the human-environment relationship.

Caught in an anthropogenic shift away from nature, fewer people develop these place-specific attachments that support the advocation for those environments (Halpenny 2010; Selhub and Logan 2014). Elain Brooks captures this simply: "Humans seldom value what they cannot name, or experience" (as cited in Louv 2011, p. 141). Similarly, Naomi Klein (2017) wrote, "You need to love something first, before you can protect and defend it" (p. 64). Selhub and Logan (2014) reason that society's systemic withdrawal from natural places immunizes humans against empathy for nature. Since sustainability is "ultimately about maintaining an intimate relationship with nature" (Selhub and Logan 2014, p. 3), people's detachment from natural places jeopardize the health of the natural world.

Until recently, parks and protected areas in North America experienced a severaldecade long stagnation or decline in visitation (National Park Service 2020; Parks Canada 2019; Stevens et al. 2014). While visitation numbers have increased, the preceeding decline generated concern amongst representatives from protected areas management teams that weakened public and political support would result (Canadian Parks Council 2014; Jager and Halpenny 2012, National Park Service 2020). Connecting humans to nature through direct exposure provides outstanding physical and psychological benefits, further educates people about the 
interconnectedness of environmental systems, bolsters environmental awareness, and fosters a desire to partake in stewardship towards the natural world (Canadian Parks Council 2014; MacKay and Schmitt 2019; Selhub and Logan 2014). Since "people need to care about the environment in order to value it, and appreciation, love, care and protection are direct outcomes of our experience of and relation to nature now, and for generations to come" (Canadian Parks Council 2014, p. 34), specific efforts to connect people to natural places became paramount. For example, the Canadian Parks Council (2014) campaigned to raise awareness concerning the extensive benefits of nature exposure, and Parks Canada focused its engagement efforts to target youth, young families, and urban and new Canadians (Parks Canada 2019). With renewed interest in visiting natural places due to the COVID-19 pandemic (O'Connell et al. 2020; Rice et al. 2020), it is increasingly important to understand how the characteristics and processes of being in natural places impacts connections to the environment and future stewardship behaviours. We now turn to examine the methodology that shaped our study.

\section{Methods}

This exploratory study sought to answer two research questions: 1) How do the characteristics and processes of place-based journeys develop participants' awareness and perspectives of natural places and environmental stewardship? and, 2) How do the experiences of place-based journeys contribute to connections to places in nature and plans for future environmental stewardship? To engage this multifaceted topic, a qualitative research design, following a phenomenological approach, was used to gain an in-depth understanding of participants' experiences (Creswell and Poth 2016; Denzin and Lincoln 2018). A phenomenological research method supported our need to discover, interpret, and explore how connectedness to places in nature may foster environmental stewardship, and it welcomed the notion of multiple interpretations of reality (Creswell and Poth 2016; Denzin and Lincoln 2018). Using phenomenology, we hoped to honour what van Manen (2016) recognizes as the taken-for-granted details of daily life; that which examines the everyday world and encourages introspection.

Participants were selected through purposeful sampling (Silverman 2017). Immediately after the completion of one of three, seven to 14-day Outward Bound Canada (OBC) wilderness programs, nine of 26 potential individuals consented to participate in a telephone interview; they signed a research consent form and were then contacted by the first author. OBC is a not-for-profit, charitable, educational organization that offers urban and wilderness adventures "cultivating resilience, leadership, connections and compassion through inspiring and challenging journeys in the natural world" (Outward Bound Canada 2021, p. 1). The nine participants, who had little to no previous experience in remote, multi-day expeditions, were between the ages of 23 and 55. They each participated in a semistructured interview two to four weeks after their OBC program.

Semi-structured interviews were used to allow for a more holistic understanding of experiences and their multiple interpretations (Creswell and Poth 2016). Interviews were guided by an interview protocol (as described by Creswell 2012). This approach enabled a consistent interview structure while leaving room for participants to explore their unique 
experiences individually, and for the researcher to pose probing questions (Adams 2015). Interviews ranged from 45 to 60 minutes in length and were audio recorded to ensure the accurate representation of participants' responses. The semi-structured interviews encouraged the development and elucidation of responses in order to better understand participants' experiences and insights (Denzin and Lincoln 2018). This research was approved by the primary researcher's University's Research Ethics Board.

Next, the first author transcribed the interviews verbatim and then used an interpretive analysis approach to identify recurring themes and differences between interview responses (Blankenship 2010; Creswell and Poth 2016; Denzin and Lincoln 2018). The accuracy of quotes and interpretations of participants' responses were verified by sending each participant a draft copy of the paper for their review and approval (see Morse et al. 2002). According to Crandall et al. (2006), independent verification of findings replicated across interviews allows for greater confidence in the outcome. Finally, pseudonyms are used throughout the paper to maintain participant anonymity.

\section{Results and discussion}

Eleven themes were generated from the analyses, which were then amalgamated into the following six clusters: (1) remote and meaningful; (2) connections; (3) stewardship; (4) fear of nature itself; (5) a healthier desire; and, (6) return to nature. A discussion of each theme follows as it unpacks the aforementioned clusters. These are preceded by a brief contextualizing explanation of why participants enrolled in an $\mathrm{OBC}$ course.

\section{Initial participant motivations}

Connection to place is personal. Therefore, it is important to acknowledge the potential bias introduced while working with $\mathrm{OBC}$ participants and bring insight to reasons participants chose to enrol in an OBC journey. During the interviews, participants were asked why they chose to partake in such an experience. Doing so sought to address potentially biasing the results had participants' intentions been to connect with the natural environment, learn about stewardship, or develop their ecological knowledge. The OBC trips in which study participants engaged, however, were not specifically designed to provide education on these topics. Participants' motivations included: "I wanted something that would get me out of my comfort zone, and I really wanted to have an adventure and just go outside, travel, and grow my communication skills, self-perception, and selfconfidence." Or, included motivations like professional development, attaining a different perspective on life, a sponsored educational opportunity, and having been gifted the trip. With context to participants' motivations, the next section discusses the interview results, where themes are characterized by the clusters from which they stem.

\section{Remote and meaningful}

Three themes emerged that formed the cluster "remote and meaningful." These included the following, which are discussed below:

- Most meaningful natural experience 
- Most remote experience

- Transcendent experiences

A lasting attachment to places in nature is a feeling that resonates within an individual, extends into the future, and is perhaps one of the most important intricacies of fostering a sense of stewardship (Goralnik and Nelson 2011; Stedman 2002). Eight of the nine research participants expressed that their OBC journey was their most meaningful engagement with nature and the most remote journey they had ever taken. Together, these experiences created lasting memories that were often described in transcendent terms by participants. Williams and Harvey (2001) explain that a transcendent experience is characterized by a "sense of union and timelessness, and broader appraisal dimensions such as complexity, novelty and causality" (p. 249). Selhub and Logan (2014) similarly describe transcendent experiences as "unforgettable moments of extreme happiness, of attunement to that outside the self, and moments that are ultimately perceived as very important to the individual" (p. 18). As such, transcendent experiences can help foster a lasting attachment to place. Six of the nine participants in this study identified a transcendent moment on their expedition. For example, Jake said: "There was a mist, all out over this lake, and you could see these vortexes, almost like little whirlpools within the mist. It was brilliant. So that's one thing that will stick with me." Kathy also shared a similar experience:

I did a little stroll, and I came upon a huge bull moose lying down by his watering hole, hanging out in the sun. I immediately dropped to my knees when I saw him and sat beside this little tree. He would take a little drink and he was just enjoying his little watering hole in the sun and it was beautiful. It so impacted me.

These unprompted recollections demonstrate the powerful connections that can be formed while alone in a natural environment. Perhaps it is these moments of clarity that create meaningful, transcendent experiences and lasting memories that have strong potential to deeply connect people with natural areas.

In addition to the moments described above, a structured solo experience is incorporated into most $\mathrm{OBC}$ programs and had a lasting impact on many participants. As Connor said:

Twenty-four hours of being alone with your thoughts. That was a profound experience.... I think it has changed me. The whole experience has changed me; I'm much more relaxed about things.... I'm four weeks into term and I'm snowed on with work, but I'm viewing it in a different way; I'm not getting as stressed as I would have in the past...

Studies of these experiences explain that solo trips have long been practiced in various religions and cultures as a method for restoring a sense of self-worth, developing skills, enhancing personal growth, and fending off symptoms of mental illnesses (Bobilya 2005; Maller et al. 2006). The many positive physical, cognitive, and perspective-based constituents present in nature appear to have been contributing factors to experiences such as these. This suggests that a socially isolated experience in nature can be an effective approach to rekindling people's connection with the natural world. Creating 
an environment, often devoid of observable human impacts or distractions, in which people can reflect and establish a sense of wonder is a step towards lasting attachments to places in nature.

While socially isolated experiences were important to study participants, so was developing meaningful relationships with trip mates. In some instances, the participants spoke of the intimate and powerful relationships they shared with others in their group. For example, Chris said, "I [came] to the point where the relationships I had on the trip were the only relationships that I thought mattered, because they were the only ones who had experienced it with me." According to the Canadian Parks Council (2014), places in nature play a pivotal role in nurturing relationships, providing a foundation for social cohesion, and help foster creativity in both children and adults. The participants in this study supported these claims through the descriptions of their own meaningful experiences in nature. Next, the second cluster examines how these meaningful experiences help foster a deepened understanding of and connection to natural places.

\section{Connections}

- Deepened connections to and through nature

Participants reported deepening spiritual, ecological, and/or spatial connections with the natural environment that grew through a sense of familiarity and awareness of the places in nature in which they were immersed during their $\mathrm{OBC}$ journey. Activities that fostered these feelings included plant and animal species identification and the freedom to drink water straight from streams and lakes. For some participants, these experiences were more meaningful and impactful than they had anticipated. Will, for example, said that:

For me it's an appreciation with, a connection with - rather than just an understanding of...being in that environment, being in that space. It almost felt like it had a presence in a way, or an effect on me in a way I didn't think it would.

Participants demonstrated an awareness of the spiritual inspiration embedded in the powers of nature, wild landscapes, positive interpersonal interactions, and immersion in wilderness (see Fredrickson and Anderson 1999). With recognition of how participants developed meaningful connections with natural places, the third cluster examines how these connections fostered stewardship.

\section{Stewardship}

Participants' comments suggested three themes related to the "stewardship" cluster, including:

- Considerations for environmental employment or volunteer opportunities

- Fear of losing natural areas

- Desire to expose children to natural areas

Seven of the nine participants spoke of their interest in environmental conservation initiatives, and many were in the process of actively seeking related employment or volunteer 
opportunities. Mary said that, as a result of her expedition, she has been re-evaluating her profession as a civil engineer, wanting rather to work in nature, or at least "help preserve it directly, rather than in an indirect way." Will was the only research participant actively employed by an actively environmentally responsible organization; therefore, the trip did not seem to alter his perspective of stewardship, but reinforced his willingness to continue his environmental advocacy. James, Connor, and Will specifically discussed their desire to protect the areas they had visited during their expeditions should environmentally degrading activities target those regions. Will also expressed concern for the well-being of the natural region he visited and how his trip altered his overall perspective.

I would want to protect it; I think I would feel more emotionally, spiritually even, attached to any sort of attack on that sort of environment, or if it were to be jeopardized in any way; if the government said "We're going to start drilling in there, or build houses" - I would probably feel more so having experienced it, feel like that's something I would want to try and fight against. I think especially the area that I was in, but I think our environment as a whole across the country or even globally.

On a more personal level, James discussed how his connectedness altered his camping habits and the protection of wild places for the enjoyment of future generations. A teacher by profession, he considered ways he could engage more children to natural places; opportunities that he would not have considered before his OBC trip.

These reflections highlight how participants conceptualized and considered the impacts of their actions, and approached a sense of stewardship or environmental commitment with forethought and careful consideration for the future. Similarly, Ryan et al. (2001) found that volunteers of environmental stewardship programs indicated many significant changes in their environmental outlook and actions during their involvement in stewardship activities. Their study suggests that, "stewardship programs that consider volunteers' changing motivations at different stages of their participation can effectively nurture personal growth while fostering a powerful constituency for the environment among their volunteers" (p. 629). This suggests that exposure to places in nature (i.e., through species identification, relying on the immediate environment for drinking water, experiencing transcendent moments, etc.) can foster a nurturing for those, or other natural spaces, and demonstrates that the experiences the participants gained in nature helped to foster a sense of stewardship, which is ultimately the first step toward action.

\section{Fear of nature itself}

\section{- Journeys reduced fear}

Regardless if fears are based on perceived or actual risk, people are unlikely to visit nature if they fear elements of natural spaces. For those wanting to help foster connections between people and nature, this feedback is problematic. For the participants in this study, seven out of nine reported an initial fear of the wilderness in which they were immersed during their journey. Only once participants began to interact with the wilderness that surrounded them did they see their fears as irrational. The concept of unexplained fear shares a close connection with our understanding of the fear of the unknown, where people experience anxiety in a novel environment. Since many of the participants had never 
experienced comparably isolated environments, they were fearful throughout the anticipation stage of their trip. However, all seven of these participants reported a progressive lessening of their fears during their journey, and ultimately left the environment with it significantly reduced. For example, Sam explained:

It's the unknown...I was really fixated on the concept of grizzly bears and cougars, as were many participants in my group who were really almost obsessed with the fear of bears and cougars attacking and killing us. There was no real logic for it. Once I took the bears and the cougars out of the equation, there's really nothing to fear. But again, it was the concept of the unknown; no civilization, no electricity, no lights, no people around you, and it actually turned out to be the best part of it, because you just become completely detached from all of that crap. So yes, I think I was quite fearful before I went. And that having done especially the solo, I do not fear it at all anymore.

While most of the participants in this study shared experiences similar to Sam's, the OBC expeditions did have varying effects on their senses of security.

Of the seven people who reported a lessening of their fears throughout expedition, the majority of them said that their fears leading up to the trip were irrational, based on perceived rather than actual risks. The two participants who did not indicate a reduction of fear were those who had previous wilderness experiences, which acted as a theoretical security blanket and enabled perceptions of risk better aligned with the actual risk. In effect, these participants were not challenged by "debilitating" fears. While the participants with some wilderness experience still experienced some fear in anticipation of and at the debut of their OBC program, their fears appeared to resolve quickly. James, for example, had some outdoor experience and when he reflected a few days into the trip, said, "I think that all my apprehensions had completely gone." Literature (e.g., Berto 2014; Kondo et al. 2018) supports James' reflection, indicating that natural areas can reduce fear, anxiety, and stress. Despite the sense of security urban environments often embody, many studies have found that natural environments positively counter the negative stimuli associated with urban environments (e.g., Berto 2014; Hunter et al. 2019; Ressler 2010). This is explored further in the next cluster, which examines how meaningful journeys were shaped by the lack of technology and how these experiences resulted in difficult and often unexpected symptoms of post-trip withdrawal from nature.

\section{A healthier desire}

Two themes emerged related to "healthier desire," including:

- Freedom from technology

- Withdrawal from nature

Participants' interviews were void of comments suggesting a yearning for a return to urban life or to be technologically connected. In fact, Sam, Kathy, Mary, and Chris were all grateful for the chance to disconnect from technology. Mary also suggested that people do not recognize their reliance on technology until they disconnect from it: 
When I was coming back into the airport, into the city...you look around and everyone is looking at their cell phone-so I feel like it's easiest to connect to people who you are on trip with when you're out there [in nature] and you're not bombarded with technology. I think that people that live in the city-that there is a disconnect, and sometimes it's when you don't know it exists, when you're not aware of the disconnect, it's easy for you to not think about it and not care.

The impact of participants' experiences away from digital technology was also clear in their discussions of withdrawal from the natural environment upon their return to the city or the "daily grind." This was Chris' experience:

Usually, I would play Xbox or something for a few hours, or play guitar and stuff — but I just wanted to be outside when I got back...I just wanted to put everything on my back and go somewhere. So that was quite a struggle.

There has been a recent proliferation of research describing Western society's unfavourable attachment to technology. For example, Scott et al.'s (2017) study showed that society's use of technology negatively impacts mental health and causes decreased social skills, emotional skills, self-motivation and empathy, and may lead to increased conflicts with others. Boesveld (2018) further suggests that the popularization of technology, such as social media, decreases attention spans and increases feelings of perceived social isolation among teenagers. It has resulted in endemic social change (Boesveld 2018).

In contrast, research illustrates that exposure to natural environments releases the same chemicals in the brain that some medications, like antidepressants, strive to mimic (Di Carlo et al. 2001). Consequently, when humans return to urban environments where the human body uses fewer senses and areas of the brain than while in nature (Lee et al. 2009), experiences comparable to drug withdrawal can result (Kim et al. 2010). The participants, who reported similar experiences, said that they wished to return to places in nature to experience the cathartic release of positive emotions they experienced on their $\mathrm{OBC}$ journey. As highlighted in the above quotes, the $\mathrm{OBC}$ trips presented revolutionary experiences for many study participants. The sixth and final cluster investigates participants' desire to return to natural places.

\section{Return to nature}

\section{- Desire to continue visiting natural areas}

Eight of the nine participants confirmed that their OBC trip was the most isolated, and/ or influential wilderness they had experienced. And, despite their initial fears, all nine participants unanimously expressed their desire to continue to participate in comparable journeys, either independently or guided. Further, four of the participants expressed a need to share similar experiences in the future with their children, including participants who did not have children at the time of this research. These findings demonstrate how experiences in places in nature create a willingness to return and share them with others. However, some study participants expressed concern for barriers that could inhibit their return to environments like those through which their OBC expeditions 
travelled. Amanda, Mary, and Will, who all reside in urban environments, discussed how they had minimal opportunity to return to such isolated settings, as none of their peers nurtured a common interest in "escaping" to the outdoors, and a solo return was not of interest. Amanda said, "I don't know that many people who are both fit and like going out in nature...so I'm trying to find a group I can do that with-but I would definitely keep doing it." Amanda and Mary identified that their solution was to frequently visit natural areas near their homes and participate in other OBC trips, guided by experienced leaders. All of the study's participants expressed a positive association between their exposure to natural environments through $\mathrm{OBC}$ and their intention to continue to visit natural areas and participate in outdoor journeys.

\section{The greater picture}

A wilderness-based $\mathrm{OBC}$ expedition had a profound impact on the study participants. The experiences, insights, and knowledge elicited through the interviews restructured the manner in which participants interpreted their surroundings: their comfort levels in places in nature grew, their values associated with natural areas changed, and for a few, their journey challenged them to question their current personal and employment situation. In other words, as suggested by Beery and Wolf-Watz (2014), experience in a specific natural place assisted in the development of environmental connectedness, which several participants reported served as a motivator for their future stewardship for the environment.

Our findings are similar to those of Baird et al. (2020), who categorized the unprompted connections to places in nature on NOLS trips as either cognitive connections (i.e., awareness or knowledge of nature, attitudes, values, etc.) or emotional connections (i.e., attachment, empathy, etc.). For each research participant in this study, the OBC trip helped develop their knowledge of the natural world, increased their sense of connection with their surroundings, inspired their will to participate in employment or volunteer initiatives to improve the state of the environment, and nurtured a desire to return to natural places. Further, by the time the interviews were conducted, several of the participants were actively seeking opportunities to become involved with environmental conservation initiatives. These results indicate that participants fostered a sense of environmental stewardship; the OBC journeys provided a catalyst to pursue further engagement with environmentally conscious initiatives.

Results also indicate that the symbolic meaning of the place in which participants' journeys occurred morphed into something positive or reinforced existing meanings. This was demonstrated through participant reports of transcendent experiences, reduction of fear, deepened connections to nature, and feelings of withdrawal upon the end of the journey, suggesting that these symbolic meanings grew in importance in participants' identities. As Chapin and Knapp (2015) note, stewardship intentions are motivated by the importance of symbolic meanings to an individual's identity. While this doesn't indicate that action will occur, it does increase chances that it will, especially as recreation places may assist in the development of behaviours, social groups, and interpersonal relationships (Beery and Wolf-Watz 2014). 
The purpose of this paper was to explore how the characteristics and processes of experiences on place-based wilderness journeys develop participants' relationship with natural places and perceptions of environmental stewardship, and examine how the characteristics and processes of these experiences contribute to people's connections to natural places and forecast environmental stewardship. Findings shed light on the psychological processes (i.e., moving from fearful to not fearful, transcendental experiences) that functional, affective, and cognitive bonds with place help facilitate (Halpenny 2010).

From a qualitative perspective, results also highlight participants' development of the meaning of nature, responding to the suggestions of previous researchers (Beery and Wolf-Watz 2014; MacKay and Schmitt 2019). The study explored how the characteristics and processes of journeys in natural places impact relationships with nature and future stewardship behaviours, and also confirmed how extended journeys through places in nature interact with more profound cognitive and emotional connections to encourage future actions (Baird et al. 2020). As this research did not include follow-up interviews, future research should draw on qualitative methods to more fully explore how feelings and emotions develop during a journey and their impact on future stewardship activities. The "black box" of cultural learning processes, particularly in the confines of an outdoor recreation experience in nature, should also be examined, and include participants outside of OBC or similar programs. Finally, the impact of instructors' beliefs, attitudes, and role modeling behaviours are additional avenues for further research.

\section{Conclusion}

The participants in this study demonstrated that their experiences with Outward Bound Canada (OBC) planted a seed of inspiration within them. Importantly, as Halpenny (2010) and Baird et al. (2020) noted, individuals may extend positive feelings about a particular place to the greater environment, increasing the chance they will act to protect the environment in the future. Driven by their new sense of discovery, we are hopeful that they will engage in stewardship-based initiatives and continue to actively seek engagement with nature-based pursuits, and ultimately contribute to stewardship efforts, including sharing experiences in nature with others.

\section{Declaration}

Conflict of interest On behalf of all authors, the corresponding author states that there is no conflict of interest.

\section{References}

Adams, W. C. (2015). Conducting semi-structured interviews. In K. E. Newcomer, H. P. Hatry, \& J. S. Wholey (Eds.), Handbook of practical program evaluation (pp. 492-505). Jossey-Bass.

Aizlewood, A., Bevelander, P., \& Pendakur, R. (2006). Recreational participation among ethnic minorities and immigrants in Canada and the Netherlands. Journal of Immigrant \& Refugee Studies, 4(3), 1-32. https://doi.org/10.1300/J500v04n03_01. 
Baird, J., Hutson, G., \& Plummer, R. (2020). Examining links between connections to nature and intentions for pro-environmental behavior as outcomes of NOLS. Journal of Outdoor Recreation, Education, and Leadership, 12(4), 367-379. https://doi.org/10.18666/JOREL-2020-V12-I4-9992.

Barker, S. (2007). Ecological education: Reconnecting with nature to promote sustainable behaviours. In D. B. Zandvliet \& D. L. Fisher (Eds.), Sustainable communities, sustainable environments: The contribution of science and technology education (pp. 23-35). Sense Publishers. https://doi.org/10.1163/ 9789087901738 004.

Barton, J., \& Pretty, J. (2010). What is the best dose of nature and green exercise for improving mental health? A multi-study analysis. Environmental Science \& Technology, 44(10), 3947-3955. https://doi.org/10. 1021/es903183r.

Beery, T., \& Wolf-Watz, D. (2014). Nature to place: Rethinking the environmental connectedness perspective. Journal of Environmental Psychology, 40, 198-205. https://doi.org/10.1016/j.jenvp.2014.06.006.

Beery, T., Jönsson, K. I., \& Elmberg, J. (2015). From environmental connectedness to sustainable futures: Topophilia and human affiliation with nature. Sustainability, 7(7), 8837-8854. https://doi.org/10.3390/ su7078837.

Berto, R. (2014). The role of nature in coping with psycho-physiological stress: A literature review on restorativeness. Behavioural Sciences, 4(4), 394-409. https://doi.org/10.3390/bs4040394.

Blankenship, D. (2010). Applied research and evaluation methods in recreation. Human Kinetics.

Bobilya, A. J. (2005). Wilderness, solitude and monastic traditions. In C. E. Knapp \& T. E. Smith (Eds.), Exploring the power of solo, silence, and solitude. Association for Experiential Education. https://eric.ed. gov/?id=ED491758

Boesveld, S. (2018). Has social media become a full-time job for teen girls? Macleans. http://www.macleans. $\mathrm{ca} /$ culture/social-media-full-time-job-teen-girls/?utm_source=nl\&utm_medium=em\&utm_campaign= mme_daily\&sfi=ac73cd41313968d7f9543e34f2663a2b.

Boone, J. E., Gordon-Larsen, P., Adair, L. S., \& Popkin, B. M. (2007). Screen time and physical activity during adolescence: Longitudinal effects on obesity in young adulthood. International Journal of Behavioral Nutrition and Physical Activity, 4(1), 26-36. https://doi.org/10.1186/1479-5868-4-26.

Canadian Parks Council. (2014). Connecting Canadians with nature: An investment in the well-being of our citizens. Parks Canada. http://www.parks-parcs.ca/english/ConnectingCanadians-English_web.pdf

Cervinka, R., Röderer, K., \& Hefler, E. (2011). Are nature lovers happy? On various indicators of well-being and connectedness with nature. Journal of Health Psychology, 17(3), 379-388. https://doi.org/10.1177/ 1359105311416873.

Chapin, F. S., \& Knapp, C. N. (2015). Sense of place: A process for identifying and negotiating potentially contested visions of sustainability. Environmental Science \& Policy, 53(A), 38-46. https://doi.org/10. 1016/j.envsci.2015.04.012.

Chipeniuk, R. (1995). Childhood foraging as a means of acquiring competent human cognition about biodiversity. Environment and Behaviour, 27(4), 490-512. https://doi.org/10.1177/0013916595274003.

Christensen, J. H., Carter, T. R., \& Giorgi, F. (2002). Prudence employs new methods to assess European climate change. American Geophysical Union, 83(13), 126-147. https://doi.org/10.1029/2002EO000094.

Crandall, B., Klein, G., \& Hoffman, R. R. (2006). Working minds: A practitioner's guide to cognitive task analysis. MIT Press.

Creswell, J. W. (2012). Educational research: Planning, conducting, and evaluating quantitative and qualitative research (4th $\mathrm{ed}$.). Pearson Education.

Creswell, J., \& Poth, C. N. (2016). Qualitative inquiry \& research design: Choosing among five approaches (4th ed.). Sage Publishing.

Daily, G. C. (2012). Nature's services: Societal dependence on natural ecosystems. Island Press.

Daily, G. C., Söderqvist, T., Aniyar, S., Arrow, K., Dasgupta, P., Ehrlich, P. R., Folke, C., Jansson, A., Jansson, B.-O., Kautsky, N., Levin, S., Lubchenco, J., Mäler, K.-G., Simpson, D., Starrett, D., Tilman, D., $\&$ Walker, B. (2000). The value of nature and the nature of value. Science, 289(5478), 395-396. https:// doi.org/10.1126/science.289.5478.395.

Denzin, N. K., \& Lincoln, Y. S. (2018). The sage handbook of qualitative research (5th ed.). Sage Publications.

Di Carlo, G., Borrelli, F., Ernst, E., \& Izzo, A. A. (2001). St John's wort: Prozac from the plant kingdom. Trends in Pharmacological Sciences, 22(6), 292-297. https://doi.org/10.1016/S0165-6147(00)01716-8.

Ewert, A., \& Davison, C. (2017). Behaviour and group management in outdoor adventure education: Theory, research and practice. Routledge. https://doi.org/10.4324/9781315677538.

Fredrickson, L. M., \& Anderson, D. H. (1999). A qualitative exploration of the wilderness experience as a source of spiritual inspiration. Journal of Environmental Psychology, 19(1), 21-39. https://doi.org/10. 1006/jevp.1998.0110. 
Goralnik, L., \& Nelson, M. P. (2011). Framing a philosophy of environmental action: Aldo Leopold, John Muir, and the importance of community. Journal of Environmental Education, 42(3), 181-192. https:// doi.org/10.1080/00958964.2010.526152.

Grimm, N. B., Faeth, S. H., Golubiewski, N. E., Redman, C. L., Wu, J., Bai, X., \& Briggs, J. M. (2008). Global change and the ecology of cities. Science, 319(5864), 756-760. https://doi.org/10.1126/science. 1150195 .

Halpenny, E. A. (2010). Pro-environmental behaviours and park visitors: The effect of place attachment. Journal of Environmental Psychology, 30(4), 409-421. https://doi.org/10.1016/j.jenvp.2010.04.006.

Hidalgo, M. C., \& Hernandez, B. (2001). Place attachment: Conceptual and empirical questions. Journal of Environmental Psychology, 21(3), 273-281. https://doi.org/10.1006/jevp.2001.0221.

Hill, A., \& Brown, M. (2014). Intersections between place, sustainability and transformative outdoor experiences. Journal of Adventure Education and Outdoor Learning, 14(3), 217-232. https://doi.org/ 10.1080/14729679.2014.918843.

Hunter, M. R., Gillespie, B. W., \& Chen, S. Y. (2019). Urban nature experiences reduce stress in the context of daily life based on salivary biomarkers. Frontiers in Psychology, 10, 1-16. https://doi.org/10.3389/ fpsyg.2019.00722.

Jager, E., \& Halpenny, E. (2012). Supporting the CBD Aichi biodiversity conservation targets through park tourism: A case study of parks Canada's visitor experience programme. PARKS: The International Journal of Protected Areas and Conservation, 18(2), 78-91. https://doi.org/10.2305/IUCN.CH.2012. PARKS-18-2.EJ.en.

Kareiva, P. (2008). Ominous trends in nature recreation. Proceedings of the National Academy of Sciences, 105(8), 2757-2758. https://doi.org/10.1073/pnas.0800474105.

Kim, T. H., Jeong, G. W., Baek, H. S., Kim, G. W., Sundaram, T., Kang, H. K., \& Song, J. K. (2010). Human brain activation in response to visual stimulation with rural and urban scenery pictures: A functional magnetic resonance imaging study. Science of the Total Environment, 408(12), 2600-2607. https://doi. org/10.1016/j.scitotenv.2010.02.025.

Klein, N. (2017). No is not enough: Resisting the new shock politics and winning the world we need. Knoff Canada: Alfred A.

Kondo, M. C., Jacoby, S. F., \& South, E. C. (2018). Does spending time outdoors reduce stress? A review of real-time stress response to outdoor environments. Health \& Place, 51(May), 136-150. https://doi.org/10. 1016/j.healthplace.2018.03.001.

Lee, J., Park, B. J., Tsunetsugu, Y., Kagawa, T., \& Miyazaki, Y. (2009). Restorative effects of viewing real forest landscapes, based on a comparison with urban landscapes. Scandinavian Journal of Forest Research, 24(3), 227-234. https://doi.org/10.1080/02827580902903341.

Louv, R. (2008). Last child in the woods: Saving our children from nature-deficit disorder. Algonquin Books of Chapel Hill.

Louv, R. (2011). The nature principle: Human restoration and the end of nature-deficit disorder. Algonquin Books of Chapel Hill.

Lumber, R., Richardson, M., \& Sheffield, D. (2017). Beyond knowing nature: Contact, emotion, compassion, meaning, and beauty are pathways to nature connection. PLoS One, 12(5), e0177186. https://doi.org/10. 1371/journal.pone.0177186.

MacKay, C. M. L., \& Schmitt, M. T. (2019). Do people feel connected to nature do more to protect it? A metaanalysis. Journal of Environmental Psychology, 65, 1-9. https://doi.org/10.1016/j.jenvp.2019.101323.

Maller, C., Townsend, M., Pryor, A., Brown, P., \& St Leger, L. (2006). Healthy nature healthy people: 'Contact with nature; as an upstream health promotion intervention for populations. Health Promotion International, 21(1), 45-54. https://doi.org/10.1093/heapro/dai032.

Manning, R. E. (2011). Studies in outdoor recreation: Search and research for satisfaction. Oregon State University Press. muse.jhu.edu/book/1583.

Mannion, G., Fenwick, A., \& Lynch, J. (2013). Place-responsive pedagogy: Learning from teachers' experiences of excursions in nature. Environmental Education Research, 19(6), 792-809. https://doi. org/10.1080/13504622.2012.749980.

Martin, K. (2011). Electronic overload: The impact of excessive screen use on child and adolescent health and wellbeing. Government of Western Australia, Department of Sport and Recreation. https://api. semanticscholar.org/CorpusID:75220143

Martin, B., Breunig, M., Wagstaff, M., \& Goldenberg, M. (2017). Outdoor leadership: Theory and practice ( $2^{\text {nd }}$ ed.). Human Kinetics.

Morse, J. M., Barrett, M., Mayan, M., Olson, K., \& Spiers, J. (2002). Verification strategies for establishing reliability and validity in qualitative research. International Journal of Qualitative Methods, 1(2), 13-22. https://doi.org/10.1177/160940690200100202. 
National Outdoor Leadership School. (2020). Our mission and values. http://www.nols.edu/en/about/mission/ National Park Service (2020). National park visitation tops 327 million in 2019. https://www.nps.gov/orgs/ 1207/2019-visitation-numbers.htm

Nisbet, E. K., Zelenski, J. M., \& Murphy, S. A. (2009). The nature relatedness scale: Linking individuals' connection with nature to environmental concern and behaviour. Environment and Behaviour, 41(5), 715-740. https://doi.org/10.1177/0013916508318748.

O'Connell, T. S., Howard, R. A., \& Hutson, G. (2020). The impact of COVID-19 on outdoor recreation participation in Canada - Initial report on a national study of outdoor recreationists. Brock University, St. Catharines, Ontario, Canada. https://brocku-my.sharepoint.com/:b:/g/personal/toconnell_brocku_ca/ EY_WRVUFiQ1FsrRnCxOB3AcBRUvDk4uBbHGZ117oUNyzwQ?e=uQbPto

Outward Bound Canada. (2021). Our mission. http://www.outwardbound.ca

Parks Canada. (2019). 2019-20 Departmental Plan. Government of Canada. https://www.pc.gc.ca/en/agenceagency/bib-lib/plans/dp/dp2019-20/index

Pergams, O. R., \& Zaradic, P. A. (2008). Evidence for a fundamental and pervasive shift away from naturebased recreation. Proceedings of the National Academy of Sciences, 105(7), 2295-2300. https://doi.org/ 10.1073/pnas.0709893105.

Ressler, K. J. (2010). Amygdala activity, fear, and anxiety: Modulation by stress. Biological Psychiatry, 67(12), 1117-1119. https://doi.org/10.1016/j.biopsych.2010.04.027.

Rice, W. L., Meyer, C., Lawhon, B., Taff, B. D., Mateer, T., Reigner, N., \& Newman, P. (2020). The COVID19 pandemic is changing the way people recreate outdoors. Preliminary report on a national survey of outdoor enthusiasts amid the COVID-19 pandemic. Retrieved from https://nt.org/research-resources/ leave-no-trace-covid-19-research/

Ryan, R. L., Kaplan, R., \& Grese, R. E. (2001). Predicting volunteer commitment in environmental stewardship programmes. Journal of Environmental Planning and Management, 44(5), 629-648. https://doi.org/10.1080/09640560120079948.

Samba, M., \& Seucharan, C. (2020, August 5). Officials, advocates working to end 'shenanigans' of campers heading in droves to Canada's backcountry. The Globe and Mail. https:/www.theglobeandmail.com/ canada/article-officials-advocates-working-to-end-shenanigans-of-campers-heading/

Samuelsson, K., Barthel, S., Colding, J., Macassa, G., \& Giusti, M. (2020). Urban nature as a source of resilience during social distancing amidst the coronavirus pandemic. Landscape and Urban Planning, (preprint). https://doi.org/10.31219/osf.io/3wx5a.

Schultz, P. W., Gouveia, V. V., Cameron, L. D., Tankha, G., Schmuck, P., \& Franěk, M. (2005). Values and their relationship to environmental concern and conservation behavior. Journal of Cross-Cultural Psychology, 36(4), 457-475. https://doi.org/10.1177/0022022105275962.

Scott, D. A., Valley, B., \& Simecka, B. A. (2017). Mental health concerns in the digital age. International Journal of Mental Health Addiction, 15(3), 604-613. https://doi.org/10.1007/s11469-016-9684-0.

Selhub, E. M., \& Logan, A. (2014). Your brain on nature: The science of nature's influence on your health, happiness and vitality. John Wiley.

Silverman, D. (2017). Doing qualitative research: A practical handbook (5 $5^{\text {th }}$ edition). Sage Publications.

Statistics Canada. (2017, February 23). Immigration and diversity: Population projections for Canada and its Regions, 2011 to 2036. http://www.statcan.gc.ca/pub/91-551-x/91-551-x2017001-eng.htm

Stedman, R. (2002). Toward a social psychology of place: Predicting behavior from place-based cognitions, attitude, and identity. Environment and Behavior, 34(5), 561-581. https://doi.org/10.1177/ 0013916502034005001.

Stevens, T. H., More, T. A., \& Markowski-Lindsay, M. (2014). Declining national park visitation: An economic analysis. Journal of Leisure Research, 46(2), 153-164. https://doi.org/10.1080/00222216. 2014.11950317.

United Nations. (2014). World Urbanization Prospects: The 2014 Revision, Methodology. Working paper no. ESA/P/WP.238. https://population.un.org/wup/Publications/Files/WUP2014-Methodology.pdf

van Manen, M. (2016). Researching lived experience: Human science for an action sensitive pedagogy (2 $2^{\text {nd }}$ ed). Routledge. https://doi.org/10.4324/9781315421056.

Vaske, J. J., \& Kobrin, K. C. (2001). Place attachment and environmentally responsible behavior. The Journal of Environmental Education, 32(4), 16-21. https://doi.org/10.1080/00958960109598658.

White, D. D., Virden, R. J., \& van Riper, C. J. (2008). Effects of place identity, place dependence, and experience-use history on perceptions of recreation impacts in a natural setting. Environmental Management, 42(4), 647-657. https://doi.org/10.1007/s00267-008-9143-1.

Williams, K., \& Harvey, D. (2001). Transcendent experience in forest environments. Journal of Environmental Psychology, 21(3), 249-260. https://doi.org/10.1006/jevp.2001.0204. 
Wyles, K. J., White, M. P., Hattam, C., Pahl, S., King, H., \& Austen, M. (2019). Are some natural environments more psychologically beneficial than others? The importance of type and quality on connectedness to nature and psychological restoration. Environment and Behaviour, 51(2), 111-143. https://doi.org/10.1177/0013916517738312.

Publisher's note Springer Nature remains neutral with regard to jurisdictional claims in published maps and institutional affiliations.

Nicholas R. Schwass, MES is a graduate from the Environmental Studies program in the School of Outdoor Recreation, Parks and Tourism at Lakehead University in Thunder Bay, Ontario, Canada. His research interests bifurcate between environmental pedagogy and discovering factors that create natural connections, foster stewardship, and create a love of place. He is currently a teacher with the Bluewater District School Board in Ontario.

Stephanie E. Potter, MES is a graduate from the Environmental Studies program at Lakehead University in Thunder Bay. With attention to critical feminist philosophy, her interests include parks and protected areas management, polar tourism management, and social justice, particularly as it is affected by outdoor experiences.

Timothy S. O'Connell , PhD is a Professor in the Department of Recreation and Leisure Studies at Brock University in St. Catharines, Ontario, Canada. He teaches outdoor recreation, outdoor leadership and outdoor education. His research interests include psychological sense of community in organized outdoor pursuits groups, sense of place, reflective practice, and impacts of participation in outdoor orientation programs. Tim is a 3M National Teaching Fellow.

Tom G. Potter , PhD is a Professor in the School of Outdoor Recreation, Parks and Tourism at Lakehead University in Thunder Bay, Ontario, Canada. His teaching and research interests blend to include the pedagogy of outdoor education, outdoor leadership, risk management, social justice, transportation safety, environmental stewardship, and nature-based therapy.

\section{Affiliations}

\section{Nicholas R. Schwass ${ }^{1} \cdot$ Stephanie E. Potter ${ }^{1} \cdot$ Timothy S. O'Connell $^{2} \cdot$ Tom G. $^{\prime}$. Potter $^{1}$}

Stephanie E. Potter

sepotter@lakeheadu.ca

Timothy S. O'Connell

tim.oconnell@brocku.ca

Tom G. Potter

tom.potter@lakeheadu.ca

1 School of Outdoor Recreation, Parks and Tourism, Lakehead University, 955 Oliver Road, Thunder Bay, Ontario P7B 5E1, Canada

2 Department of Recreation and Leisure Studies, Brock University, 1812 Sir Isaac Brock Way, St. Catharines, Ontario L2S 3A1, Canada 